\title{
Congenital Sucrase-Isomaltase Deficiency Identification of a Glutamine to Proline Substitution That Leads to a Transport Block of Sucrase-Isomaltase in a Pre-Golgi Compartment
}

\author{
Joke Ouwendijk, ${ }^{\star}$ Catharina E.C. Moolenaar, ${ }^{\ddagger}$ Wilma J. Peters, ${ }^{\star}$ Cornelis P. Hollenberg, ${ }^{\ddagger}$ Leo A. Ginsel, ${ }^{\star}$ Jack A.M. Fransen, ${ }^{\star}$ \\ and Hassan Y. Naim ${ }^{\ddagger}$ \\ *Department of Cell Biology and Histology, University of Nijmegen, 6500 HB Nijmegen, The Netherlands; and ${ }^{\ddagger}$ Institute of Microbiology, \\ Heinrich-Heine University of Düsseldorf, D-40225 Düsseldorf, Germany
}

\begin{abstract}
Congenital sucrase-isomaltase deficiency is an example of a disease in which mutant phenotypes generate transportincompetent molecules. Here, we analyze at the molecular level a phenotype of congenital sucrase-isomaltase deficiency in which sucrase-isomaltase (SI) is not transported to the brush border membrane but accumulates as a mannoserich precursor in the endoplasmic reticulum (ER), ERGolgi intermediate compartment, and the cis-Golgi, where it is finally degraded. A $6-\mathrm{kb}$ clone containing the fulllength cDNA encoding SI was isolated from the patient's intestinal tissue and from normal controls. Sequencing of the cDNA revealed a single mutation, $\mathrm{A} / \mathrm{C}$ at nucleotide 3298 in the coding region of the sucrase subunit of the enzyme complex. The mutation leads to a substitution of the glutamine residue by a proline at amino acid 1098 (Q1098P). The Q1098P mutation lies in a region that is highly conserved between sucrase and isomaltase from different species and several other structurally and functionally related proteins.

This is the first report that characterizes a point mutation in the SI gene that is responsible for the transport incompetence of SI and for its retention between the ER and the Golgi. (J. Clin. Invest. 1996. 97:633-641.) Key words: ERGIC-53 • intestine • processing • quality control $\bullet$ retention
\end{abstract}

\section{Introduction}

The highly organized cascade of processing and modification events along the biosynthetic pathway of secretory and membrane proteins has led to the general concept of compartmentalization of the cell into structurally and functionally distinct organelles (1-4). Conformational modifications of membrane and secretory proteins commence already during their translo-

\footnotetext{
Address correspondence to Dr. Hassan Y. Naim, Institute of Microbiology, Heinrich-Heine University of Düsseldorf, Universtätsstrasse 1, Geb. 26.12, D-40225 Düsseldorf, Germany. Phone: 211-8113733/3586; FAX: 211-811-3733/5370; E-mail: hassan.naim@uni_duesseldorf.de

Received for publication 11 September 1995 and accepted in revised form 30 October 1995.
}

J. Clin. Invest.

(C) The American Society for Clinical Investigation, Inc.

0021-9738/96/02/0633/09 \$2.00

Volume 97, Number 3, February 1996, 633-641 cation across the endoplasmic reticulum $(\mathrm{ER})^{1}$ membrane and continue in the ER lumen (4-6). Among the most important modifications are those elicited by cotranslational glycosylation, inter- or intramolecular disulfide bond formation, and subunit assembly known as oligomerization $(5,7,8)$. These events are considered to be rate limiting along the exocytic pathway. However, modifications in the Golgi, such as acquisition of a complex type of oligosaccharides, have been frequently reported to confer effects also on the transport kinetics of proteins to the cell surface and secretion into the external milieu (9-12). Analysis and identification of the various steps of the secretory pathway and dissection of the molecular mechanisms adequate for efficient transport of membrane and secretory proteins to the cell surface have been successfully investigated in naturally occurring mutant phenotypes of proteins with impaired targeting (for review see reference 13).

Congenital sucrase-isomaltase deficiency (CSID) has been used to characterize various steps in the biosynthesis, transport, and sorting of sucrase-isomaltase (SI) as a model for cell surface membrane proteins (14-17). CSID is an autosomal recessive disorder of the small intestine that is clinically manifested as a watery osmotic-fermentative diarrhea upon ingestion of di- and oligosaccharides. Epithelial cells of patients with this disease lack the sucrase activity of the enzyme SI, while the isomaltase activity can vary from absent to practically normal.

SI is a type II integral membrane glycoprotein that is exclusively expressed in the small intestinal microvillar membrane (18) and is responsible for the terminal digestion of dietary sucrose and starch (for review see reference 19). The glycoprotein comprises two subunits that are highly homologous and are thought to be derived from the same ancestral gene (20). These two subunits are associated with each other by strong noncovalent, ionic interactions $(19,21)$. SI is synthesized in the rough ER as a single chain mannose-rich precursor comprising both subunits (pro-SIh, $210 \mathrm{kD}$ ) (22). It is transported to the Golgi apparatus at a relatively slow rate and does not form homodimers before ER exit (11). The strong homologies between the two main domains suggest that quasi-dimers or pseudo-dimers (8) are formed, which are presumably sufficient for acquisition of transport competence. After modification of the $\mathrm{N}$-linked glycans and $O$-glycosylation, $\mathrm{SI}$ is sorted to the

1. Abbreviations used in this paper: AMV, avian myeloblastosis virus; ApN, aminopeptidase N; CSID, congenital sucrase-isomaltase deficiency; Endo F/GF; Endo- $N$-acetylglucosaminidase F/glycopeptidase F; Endo H, Endo- $N$-acetylglucosaminidase $\mathrm{H}$; ER, endoplasmic reticulum; ERGIC, ER-Golgi intermediate compartment; LPH, lactasephlorizin hydrolase; SI, sucrase-isomaltase. 
apical membrane and cleaved in situ by lumenal pancreatic proteases to its two active subunits, sucrase and isomaltase $(22,23)$

The molecular basis of CSID is still not elucidated. However, it has been proposed that different molecular defects or mutations in the SI gene are responsible for CSID (24). This hypothesis has been strongly supported by the analysis of several cases of CSID, which has led to the identification of five different phenotypes of SI $(14,17)$. Phenotypes I and II, for instance, are characterized by an intracellular accumulation of mannose-rich SI in the ER and the Golgi, respectively. In phenotype III an enzymatically inactive, but transport-competent, SI is expressed. Phenotype IV expresses a partially folded, mannose-rich SI molecule that is missorted to the basolateral membrane. Finally, phenotype V reveals an SI species that undergoes intracellular degradation leaving behind the isomaltase subunit that is correctly targeted to the brush border membrane. In this paper we analyzed a biopsy specimen of CSID phenotype II and demonstrated that SI is located in the $\mathrm{ER}$, the intermediate compartment and the cis-Golgi. We show for the first time that a single point mutation is responsible for the impaired transport behavior of SI.

\section{Methods}

Antibodies. Four epitope-specific mAbs directed against sucrase, isomaltase, or SI were used (25). These antibodies were products of the following hybridomas: HBB 1/691, HBB 2/614, HBB 2/219, and HBB 3/705. mAb anti-human lactase-phlorizin hydrolase ( $\mathrm{mAb}$ anti-LPH) and $\mathrm{mAb}$ anti-human aminopeptidase $\mathrm{N}(\mathrm{mAb}$ anti-ApN) were products of hybridomas HBB 1/909 and HBB 3/153, respectively (25). $\mathrm{mAb}$ anti-ER-Golgi intermediate compartment-53 (anti-ERGIC53) was a product of hybridoma G1/93 (26). All mAbs were generously provided by Dr. H. P. Hauri (Biocenter, Basel, Switzerland) and Dr. E. E. Sterchi (University of Bern, Bern, Switzerland).

Cell lines. Caco-2 cells (ATCC HTB-37) were cultured in Dulbecco's modified Eagle's medium (DME) supplemented with $20 \%$ heat-inactivated fetal calf serum (FCS), $1 \%$ nonessential amino acids and antibiotics (all from GIBCO BRL, Gaithersburg, MD). Monkey kidney COS-1 (ATCC CRL-1650) cells were cultured in DME supplemented with $10 \%$ FCS and antibiotics. All cell lines were cultured at $37^{\circ} \mathrm{C}$ in a humidified $5 \% \mathrm{CO}_{2}$ incubator.

Processing of biopsy samples. The patient with CSID had a lifelong history of abdominal pain, cramps, and osmotic diarrhea upon ingestion of sucrose. CSID was assessed by the breath hydrogen test and by sucrose tolerance test. CSID was further confirmed by enzyme activity measurements of sucrase and isomaltase in intestinal biopsy homogenates (27). Control intestinal tissue was taken from patients screened for diagnostic purposes other than CSID. Peroral suction intestinal biopsy samples from CSID and controls were taken from the upper jejunum and were histologically normal. Five biopsy samples were obtained from each patient and immediately processed as follows. One sample was cut into small pieces and fixed for immunoelectronmicroscopy (see later). One sample was frozen in liquid nitrogen for RNA preparation. Three samples were biosynthetically labeled in organ tissue culture dishes (Falcon Division, Becton Dickinson, Lincoln Park, NJ) on stainless steel grids according to Naim et al. (28). Here, the tissue was labeled continuously with $150 \mu \mathrm{Ci}$ of $\left[{ }^{35} \mathrm{~S}\right] \mathrm{me}-$ thionine (trans- $\left.{ }^{35} \mathrm{~S}\right]$ methionine, $>1,000 \mu \mathrm{Ci} / \mathrm{mmol}$; ICN Biomedicals, Inc., Carson, CA) for 0.5 , 4, or $18 \mathrm{~h}$. After the labeling periods, the specimens were washed three times in RPMI 1640 (GIBCO BRL) and homogenized at $4^{\circ} \mathrm{C}$ with a Teflon glass homogenizer in $1 \mathrm{ml}$ of homogenization buffer ( $25 \mathrm{mM}$ Tris- $\mathrm{HCl}, 50 \mathrm{mM} \mathrm{NaCl}, \mathrm{pH} 8.1$ ), and a cocktail of protease inhibitors containing $1 \mathrm{mM}$ PMSF, $1 \mu \mathrm{g} / \mathrm{ml}$ pepstatin, $5 \mu \mathrm{g} / \mathrm{ml}$ leupeptin, $17.4 \mu \mathrm{g} / \mathrm{ml}$ benzamidine, and $1 \mu \mathrm{g} / \mathrm{ml}$ apro- tinin (all from Sigma Immunochemicals, St. Louis, MO). The homogenates were either further processed directly for immunoprecipitation or kept frozen at $-20^{\circ} \mathrm{C}$ until use.

Synthesis and construction of cDNA encoding pro-SI from Caco-2 cells and from tissue of control individuals and CSID patients. Reagents and methods for routine recombinant DNA techniques and PCR were as described previously $(29,30)$. Cloning of the SI cDNA from the patient's mucosal cells, control biopsies, and Caco-2 cells followed a similar strategy. Total RNA isolation and cDNA synthesis were performed as described by Moolenaar et al. (31). Total RNA was isolated from postconfluent Caco-2 cells using the guanidiniumisothiocyanate method (32). Randomly primed cDNA was synthesized from $10 \mu \mathrm{g}$ total RNA by avian myeloblastosis virus (AMV) reverse transcriptase (AMV-RT; Boehringer Mannheim Corp., Indianapolis, IN). mRNA was incubated for $60 \mathrm{~min}$ at $37^{\circ} \mathrm{C}$ in $50 \mathrm{mM}$ Tris/HCl (pH 8.3), $40 \mathrm{mM} \mathrm{KCl,} 6 \mathrm{mM} \mathrm{MgCl} 2,2.5 \mathrm{mM}$ DTT, $1 \mathrm{mM}$ dNTP (Boehringer Mannheim Corp.) in the presence of $200 \mathrm{ng}$ random primers and $25 \mathrm{U}$ AMV-RT. The negative control underwent the same procedure, only AMV-RT was excluded from the reaction mixture. For each PCR reaction 1/10 $(2 \mu \mathrm{l})$ of the reaction mixture was used as a template. PCR reactions were performed as described by Innis et al. (33) with minor modifications. Briefly, cDNA templates were amplified in a total volume of $100 \mu \mathrm{l}$ containing, $10 \mathrm{mM}$ Tris/ $\mathrm{HCl}(\mathrm{pH} 8.3), 25 \mathrm{mM} \mathrm{KCl}, 1.5 \mathrm{mM} \mathrm{MgCl}_{2}, 140 \mathrm{mM}$ of each dNTP, $700 \mathrm{nM}$ of primer, and $2 \mathrm{U}$ of Taq polymerase (Boehringer Mannheim Corp.). Double-stranded DNA was dissociated at $94^{\circ} \mathrm{C}$ for $45 \mathrm{~s}$, the annealing step was at $55^{\circ} \mathrm{C}$ for $1 \mathrm{~min}$, and the extension step was at $70^{\circ} \mathrm{C}$ for $1.5 \mathrm{~min}$. The reactions were subjected to 30 cycles of amplification. Some of the primers used in the PCR reactions were designed based on the published sequences of the rabbit and human SI cDNA $(34,35)$. Table I shows the position of these primers within the SI cDNA. The products of two independent PCR reactions were directly or after cloning into pGEM4Z sequenced with a DNA sequencing kit according to the instructions of the manufacturer (Sequenase V. 2.0; United States Biochemical Corp., Cleveland, OH).

The various DNA fragments of wild-type SI cDNA were ligated together and cloned into the expression vector pCB7 (36) to generate the plasmid phSI encoding wild-type pro-SI. Sequencing of the DNA fragments obtained by PCR from the CSID tissue revealed a single mutation A/C at nucleotide 3298. This mutation was found in the PCR product encompassing nucleotides 2967-4201. A 619-bp (NcoI-ApaI) fragment containing this mutation was purified and exchanged with its counterpart in

Table I. Oligonucleotides Used to Synthesize Various cDNAs by PCR

\begin{tabular}{cl}
\hline DNA fragment $(\mathrm{bp})^{*}$ & \multicolumn{1}{c}{ Primers $\left(5^{\prime}-3^{\prime}\right.$ direction) } \\
\hline \multirow{2}{*}{$29-695$} & CCGGGTACCAGCCTTATCCAAGTCTG \\
& TGAGATCTGTAAGTACTGGTCA \\
$652-1366$ & GCATTGGTCCCTTAGTGTAC \\
& ATCCACACATGTTGTGTGTT \\
$1299-2066$ & ATAGGTCGACGTGCCAATGG \\
& CTGCCTTGATGATTTAACCA \\
$1952-3139$ & GATGCAACTTGGGGCATTT \\
& GGTACTTCATATCTCTTCTT \\
$2967-4201$ & GCTCGCTATTCATCCATGGG \\
& GATGGCTCATTCATATCAAT \\
$4071-4923$ & TCCAGAGCTCATGTAGCTTTC \\
& GTACTGGGGTAACCATAAATGCT \\
$4876-5555$ & TATTCAAGCAGTTCTTATGG \\
& TGTAAGTGCTGTGAAACTT
\end{tabular}

*bp numbering according to Green et al. (35). 
the wild-type phSI plasmid. The generated plasmid was denoted $\mathrm{phSIa} / \mathrm{c}$.

Transfection and metabolic labeling of COS-1 cells. COS-1 cells were either transfected by the DEAE-dextran method as described by Naim et al. (29) or via electroporation in a gene pulser (Bio-Rad Laboratories, Richmond, CA): a 0.4-cm cuvette containing $200 \mu$ licecold PBS with 1.5 million cells and $10 \mu \mathrm{g}$ DNA was exposed to $0.3 \mathrm{kV}$ and $125 \mu \mathrm{F}$. Transiently transfected COS- 1 cells were metabolically labeled with $80 \mu \mathrm{Ci} \mathrm{L-}\left[{ }^{35} \mathrm{~S}\right]$ methionine (ICN Biomedicals, Inc.) as described by Naim et al. (29). After the labeling period, the cells were washed and stored at $-70^{\circ} \mathrm{C}$ until use.

Immunoprecipitation. Homogenates of biosynthetically labeled biopsy specimens were lysed on ice by addition of Triton X-100 and sodium deoxycholate to final concentrations of $0.5 \%$ each (28). Biosynthetically labeled transfected COS- 1 cells were lysed at $4^{\circ} \mathrm{C}$ for $1 \mathrm{~h}$ in lysis buffer $(25 \mathrm{mM}$ Tris- $\mathrm{HCl}, \mathrm{pH} 8.0,50 \mathrm{mM} \mathrm{NaCl}, 0.5 \%$ Triton $\mathrm{X}-100,0.5 \%$ sodium deoxycholate, and a mixture of protease inhibitors containing $1 \mathrm{mM}$ PMSF, $1 \mu \mathrm{g} / \mathrm{ml}$ pepstatin, $5 \mu \mathrm{g} / \mathrm{ml}$ leupeptin, $17.4 \mu \mathrm{g} / \mathrm{ml}$ benzamidine, and $1 \mu \mathrm{g} / \mathrm{ml}$ aprotinin). Usually $1 \mathrm{ml}$ ice-cold lysis buffer was used for each $100-\mathrm{mm}$ culture dish $\left(\sim 2-4 \times 10^{6}\right.$ cells). Detergent extracts of cells or biopsy samples were centrifuged for $1 \mathrm{~h}$ at $100,000 \mathrm{~g}$ at $4^{\circ} \mathrm{C}$ and the supernatants were immunoprecipitated as described by Naim et al. $(17,22,28,29)$. Four epitope-specific mAbs directed against sucrase, isomaltase, or SI were used (25). These antibodies were used in the form of ascites. Usually, 0.5-1 $\mu 1$ ascites was used for each immunoprecipitation. For epitope mapping studies with four mAbs directed against SI the extracts of biopsy samples were divided into equal aliquots and each aliquot was immunoprecipitated with a different antibody.

Immunofluorescence. Cellular localization of expressed proteins in COS-1 cells was studied with cells grown on coverslips. Cells were fixed with $3 \%$ paraformaldehyde and immunolabeling was carried out after $0.1 \%$ Triton X-100 permeabilization, using $\mathrm{mAb}$ anti-SI (HBB1/614) (1:1,000) and mAb anti-ERGIC-53 (G1/93) (1:100) as the primary antibodies. The secondary antibodies used FITC-conjugated goat anti-mouse or anti-rabbit IgG (1:100), Texas red-conjugated goat anti-mouse or anti-rabbit IgG (1:200) (all were from Boehringer Mannheim Corp.). Cell surface localization of proteins was assessed in transfected cells that were incubated on ice with the primary antibody before fixation and without incubation with Triton $\mathrm{X}-100$. The cells were visualized with a confocal laser microscope using a double channel for FITC and Texas red and/or with a routine fluorescence microscope.

Immunoelectron microscopy. Biopsy samples were cut into small pieces and fixed in a mixture of $2 \%$ formaldehyde and $0.1 \%$ glutaraldehyde for $1 \mathrm{~h}$ at room temperature. They were then stored in $2 \%$ formaldehyde until use. Cryosectioning and immunolabeling with anti-SI, anti-ERGIC-53, and protein A-gold were performed as described previously $(26,37)$.

Other procedures. SDS-PAGE was performed according to the method of Laemmli (38). High molecular weight markers from Sigma Immunochemicals were used as a reference. Treatment of immunoprecipitates with Endo- $N$-acetylglucosaminidase $\mathrm{H}$ (Endo $\mathrm{H}$ ), Endo$N$-acetylglucosaminidase F/glycopeptidase F (Endo F/GF, also known as PNGase F) (both from Boehringer Mannheim Corp.) was done as described before (28).

\section{Results}

Initial assessment of CSID in the patient was achieved by the breath hydrogen test. Subsequently a biopsy specimen was taken from the upper jejunum and enzymatic activity measurements of the disaccharidases, SI, and LPH were performed. Here, no activity of sucrase or isomaltase could be detected, while the activity of LPH was in the normal range of the control tissue (16-32 IU/mg protein). Likewise, normal activity of another control brush border enzyme, ApN, was revealed in the patient's biopsy sample. Therefore, the results pointed to an enzymatic defect that is restricted to SI. Previous analyses of several cases of SI deficiency have demonstrated that SI is synthesized as in normal controls, but is not correctly processed or transported along the secretory pathway $(14,17)$. We therefore set out to analyze the biosynthesis and processing of SI in the patient's tissue. Metabolic labeling of biopsy samples and immunoprecipitation of the detergent extracts with four different epitope-specific monoclonal anti-SI antibodies revealed after $30 \mathrm{~min}$ of labeling an Endo $\mathrm{H}$-sensitive $210-\mathrm{kD}$ polypeptide that corresponds to mannose-rich pro-SI (Fig. 1, lanes 1-3). This polypeptide remained the predominantly labeled species after 4 and $18 \mathrm{~h}$ of labeling (Fig. 1, lanes 4-9). In the control biopsy specimen, by contrast, the Endo H-sensitive mannose-rich pro-SI (Fig. 1, lanes 10-12) was processed to a complex glycosylated Endo $\mathrm{H}$-resistant form after $4 \mathrm{~h}$ of labeling (Fig. 1, lanes 13-15). When comparing the metabolic labeling intensity of the patient's material after 4 and $18 \mathrm{~h}$ of labeling, no increase is observed as compared with the control (Fig. 1, lanes 4-6 and 7-9 vs. lanes 10-12 and 13-15). From these data we conclude that no processing of the patient's SI in the Golgi apparatus has occurred and that the protein is finally degraded.

To determine whether the impaired processing is the consequence of general cellular defect or is restricted to SI, the transport of other brush border proteins was investigated. ApN and LPH were synthesized and processed in the patient's intestinal cells in a fashion similar to control cells (Fig. 2, lanes 1-8). Thus, within $1 \mathrm{~h}$ of chase $\mathrm{ApN}$ was detected in the patient's biopsy sample as an Endo $\mathrm{H}$-sensitive mannose-rich 130-kD polypeptide, which was converted into an Endo H-resistant $160-\mathrm{kD}$ polypeptide after $20 \mathrm{~h}$ of chase (Fig. 2, lanes 3 and 4). Similarly no changes in the biosynthetic pattern of LPH could be observed. Here, LPH was synthesized as a 215-kD mannose-rich species that was cleaved intracellularly to the mature $160-\mathrm{kD}$ polypeptide (Fig. 2, lanes 7 and 8). Therefore, the failure of mannose-rich SI to mature to an Endo $\mathrm{H}$ resistant species is indeed restricted to this molecule and is not the result of a general cellular defect since two control proteins, ApN and LPH, were processed to their mature forms and transported normally in the patient's tissue.

\begin{tabular}{|c|c|c|c|c|c|c|c|c|c|c|c|c|c|c|c|}
\hline & \multicolumn{9}{|c|}{ CSID } & \multicolumn{6}{|c|}{ Control } \\
\hline pulse (hr.) & \multicolumn{3}{|c|}{0.5} & \multicolumn{3}{|c|}{4} & \multicolumn{3}{|c|}{18} & \multicolumn{3}{|c|}{4} & \multicolumn{3}{|c|}{18} \\
\hline Endo $\mathrm{H}$ & - & + & - & - & + & - & - & + & - & - & + & - & - & + & - \\
\hline Endo $\mathrm{F}$ & - & - & + & - & - & + & - & - & + & - & - & + & - & - & + \\
\hline $\begin{array}{ll}\mathrm{kD} & 245-1 \\
& 210- \\
& 185-1\end{array}$ & - & $=$ & $=$ & & & & & & & & & & & & \\
\hline
\end{tabular}

$\begin{array}{lllllllllllllll}1 & 2 & 3 & 4 & 5 & 6 & 7 & 8 & 9 & 10 & 11 & 12 & 13 & 14 & 15\end{array}$

Figure 1. Molecular forms of SI in CSID and in normal control. Biopsy samples from a patient with CSID (lanes 1-9) and normal control (lanes 10-15) were biosynthetically labeled for the indicated times with $\left[{ }^{35} \mathrm{~S}\right] \mathrm{methionine}$. The specimens were homogenized, solubilized, and immunoprecipitated with monoclonal anti-SI antibodies. The immunoprecipitates were subjected to SDS-PAGE on $5 \%$ slab gels without treatment (lanes 1, 4, 7, 10, and 13) or after Endo $\mathrm{H}$ (lanes 2, 5, 8, 11, and 14) or Endo F (lanes 3, 6, 9, 12, and 15) treatment. Gels were analyzed by fluorography. 


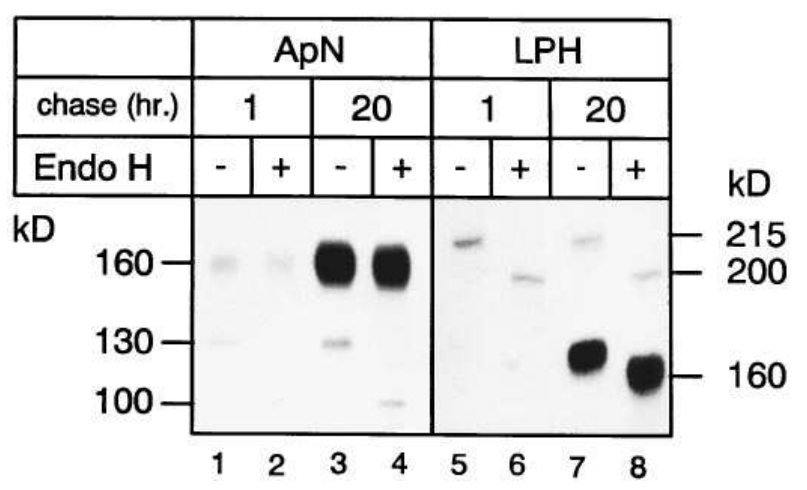

Figure 2. Biosynthesis of the control brush border glycoproteins in CSID and normal control. After the immunoprecipitations with $\mathrm{mAb}$ anti-SI in Fig. 1, the supernatants depleted from SI were immunoprecipitated sequentially with $\mathrm{mAb}$ anti-ApN (lanes 1-4) or mAb antiLPH (lanes 5-8). The immunoprecipitates were analyzed by SDSPAGE on 5\% slab gels without treatment (lanes 1,3,5, and 7) or after Endo H (lanes 2, 4, 6, and 8) treatment.

Since SI is synthesized at almost normal levels in the patient's tissue but does not mature, we wanted to determine the subcellular localization of SI in the patient's epithelial cells. Here, ultrathin cryosections of the patient's tissue were incubated with monoclonal anti-SI antibodies followed by protein A-gold. The subcellular localization was finally assessed by electron microscopy (Fig. 3). While most of the labeling in the control intestinal cells was confined to the brush border membrane, no labeling of the brush border membrane in the patient's tissue could be detected (Fig. 3, $A$ and $B$ ). Instead, intense labeling of the ER and Golgi cisternae was observed in the patient's tissue (Fig. $3 \mathrm{D}$ ), while the Golgi apparatus and the ER of the control were weakly labeled (Fig. $3 C$ ). The latter case reflects the normal steady state situation in biopsy samples (14). Finally, both specimens, the patient's as well as the control's, did not show any labeling of the basolateral membrane.

The SI labeling in the patient's cells was visible on one side of the Golgi (Fig. 3 D, arrows) and corresponds most likely to the cis-Golgi and ERGIC. This is based on the labeling pattern obtained when biopsy samples are labeled with antibodies against ERGIC-53, a marker of the cis-Golgi as well as ERGIC (Fig. 4). It should be noted that in the patient's biopsy material more label was observed for ERGIC-53 than in the control biopsies (compare Fig. 4, $A$ and $B$ ). In addition, ERGIC-53 was also observed in the cisternae on one side of the Golgi apparatus in contrast to control biopsies where only a tubulo-vesicular structure on one side of the Golgi was labeled (Fig. $4 A$; reference 26). Based on morphological criteria we conclude that the labeling of ERGIC-53 in the patient's biopsy coincides with the label of SI (compare Figs. $3 D$ and $4 B$ ), although a direct double labeling of SI and ERGIC-53 proteins could not be performed. The antibodies used to detect these proteins are both mAbs and these are difficult to combine in immunogold double staining experiments. Control experiments using antibodies against the brush border glycoproteins $\mathrm{LPH}$ and $\mathrm{ApN}$ demonstrated localization of these proteins in the apical membrane (not shown).

Altogether, the data demonstrate that in the patient's biopsy the SI molecule has egressed the ER and is arrested in an
ERGIC-53-positive, cis-Golgi compartment where it is finally degraded. The phenotype therefore resembles phenotype II of CSID described previously (17).

It is likely that the transport block of SI in the ERGIC, cisGolgi, and ER as well as the persistence as a mannose-rich polypeptide are the consequence of structural alterations in the SI molecule. To examine this possibility, we performed epitope mapping using four different epitope-specific monoclonal anti-SI antibodies, HBB 2/614, HBB 2/219, HBB 1/691, and HBB 3/705. Except for mAb HBB1/691 all other antibodies were able to recognize epitopes on mutant SI (not shown). The results imply that the epitope of HBB 1/619 did not mature in the patient's SI and was altered. Drastic alterations in the protein folding of SI did not presumably take place, since three out of four antibodies have recognized the mutant SI.

To analyze the molecular defects in this phenotype, we cloned the full-length cDNA encoding wild-type SI from Caco- 2 cells and from the patient's biopsy sample. Construction of full-length cDNA encoding wild-type SI was performed by combining two approaches. The first used conventional screening of a $\lambda \mathrm{gt}-11$ expression library made from the colon carcinoma cell line, Caco-2. Here, a clone comprising 1486 bp from nucleotides 550 to 2036 (base pair numbering according to Green et al. [35]) and covering almost $50 \%$ of the isomaltase subunit was isolated. This clone was denoted IM21.1 (Lacey, S.W., unpublished observations). In the second approach we made use of the published sequences of rabbit and human SI $(20,34)$. Many oligonucleotides were designed and used to amplify SI DNA fragments using RT-PCR on RNA extracted from Caco- 2 cells or biopsy samples. These fragments and the IM21.1 clone were ligated together to generate the full-length pro-SI cDNA. Sequencing of this clone revealed two nucleotide differences versus the published sequence (34). These differences are not due to PCR artifacts, as assessed by sequencing of PCR products of two independent $\mathrm{PCR}$ reactions. One difference is $\mathrm{A} / \mathrm{G}$ at nucleotide 4001 which represents a silent mutation. The second variation, a $\mathrm{C} / \mathrm{G}$ at nucleotide 3612 , leads to a glutamic acid instead of glutamine at amino acid 1203 in the sucrase subunit. Comparison with the amino acid sequences of rat and rabbit and our patient's (see below) sucrase subunits revealed also a glutamic acid residue at this particular position. Moreover, the human and rabbit isomaltase also contained a glutamic acid in the corresponding homologous stretch. Therefore, it is likely that the glutamine/glutamic acid exchange represents a polymorphism in the published sequence. To test the full-length cDNA, it was cloned into the pCB7 expression vector and transiently expressed in COS- 1 cells. Metabolic labeling of these cells showed that SI is processed as in normal control samples (Fig. 5, lanes 1-3, compare with Fig. 1, lanes 10-15). Also, when expressed in COS-1 cells, cell surface expression could be observed (Fig. 6, $A$ and $B$ ).

To isolate a full-length SI cDNA encoding SI in the CSID tissue, a similar strategy was followed as for wild-type SI. The PCR products derived from two independent reactions were cloned and sequenced. The sequence analysis revealed one alteration relative to the SI cDNA cloned from Caco- 2 cells. This alteration, $\mathrm{A} / \mathrm{C}$ at nucleotide 3298 , was found in the sequence encoding the $\mathrm{S}$ of the SI complex and resulted in a substitution of the glutamine 1098 by a proline (Q1098P). The mutation was confirmed by direct sequencing of several independent PCR products. The wild-type sequence could never 

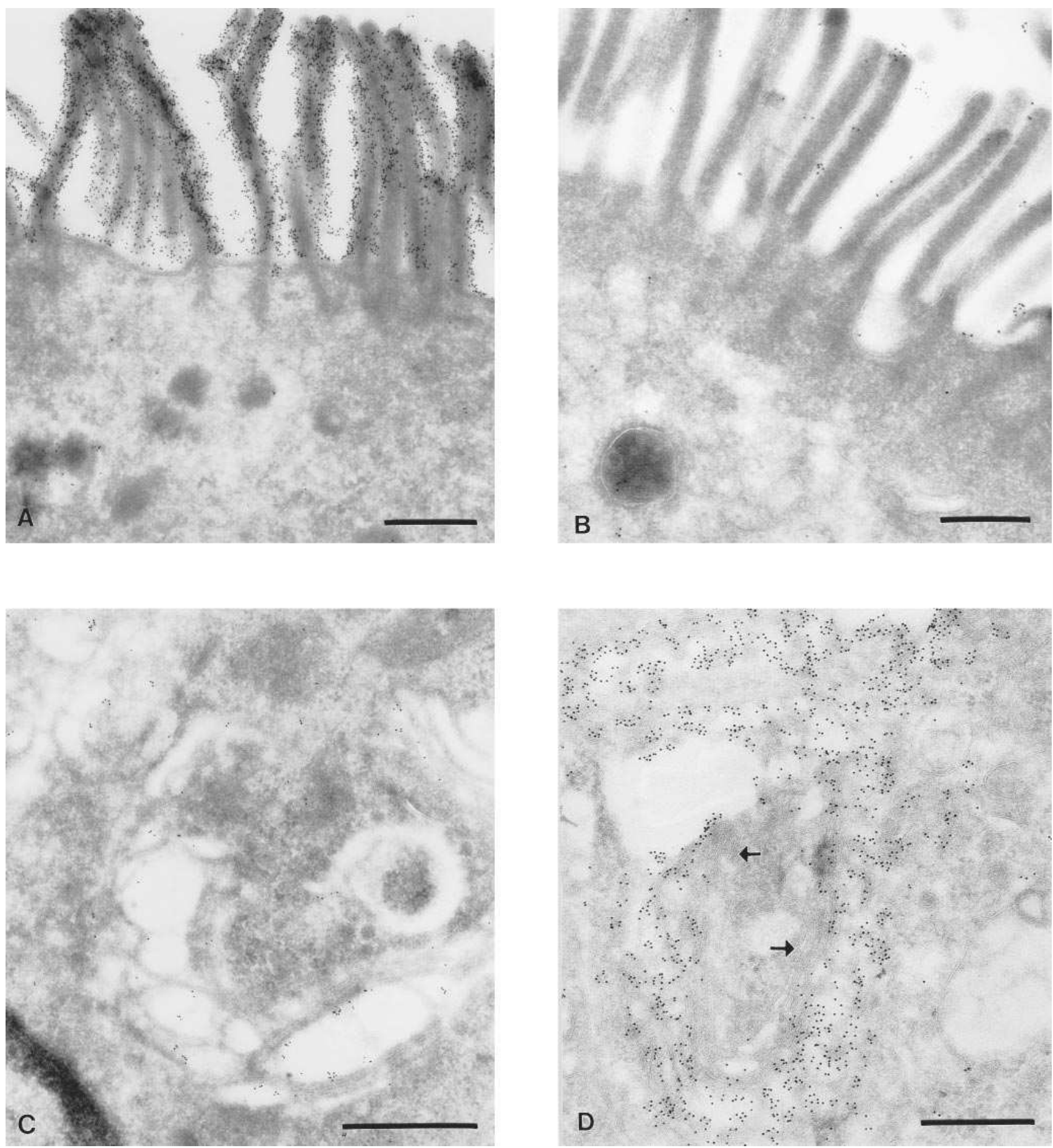

Figure 3. Immunocytochemical localization of SI in CSID and normal control. SI was localized in ultrathin cryosections from a control biopsy $(A$ and $C$ ), and from the patient's biopsy $(B$ and $D$ ), using antibody HBB $2 / 614$, followed by rabbit anti-mouse and protein A-10 nm gold staining. $(A)$ Brush border staining observed in a control biopsy; $(B)$ brush border staining observed in the patient's biopsy; $(C)$ Golgi staining observed in a control biopsy; and $(D)$ Golgi staining observed in the patient's biopsy. Note the strong accumulation of SI in this compartment. Also note that always a few cisternae on one side of the Golgi apparatus (arrows) are devoid of label. Bar, $0.5 \mu \mathrm{m}$.

be identified, suggesting that both alleles of the SI gene contain this mutation or, more likely, that one allele is not expressed.

The patient's cDNA was also cloned into the expression vector pCB7 and transiently expressed into COS-1 cells. Again, metabolically labeled COS-1 cells showed that mutant
cDNA is processed as in the patient's biopsy (Fig. 5, lanes 4-6, compare with Fig. 1, lanes 1-9). In addition, localization studies showed that the patient's SI is not expressed at the cell surface of COS-1 cells, but instead accumulates intracellularly in the ER and ERGIC, as shown by immuno double-labeling on transiently transfected cells (Fig. 6, $C$ and $D$ ). 

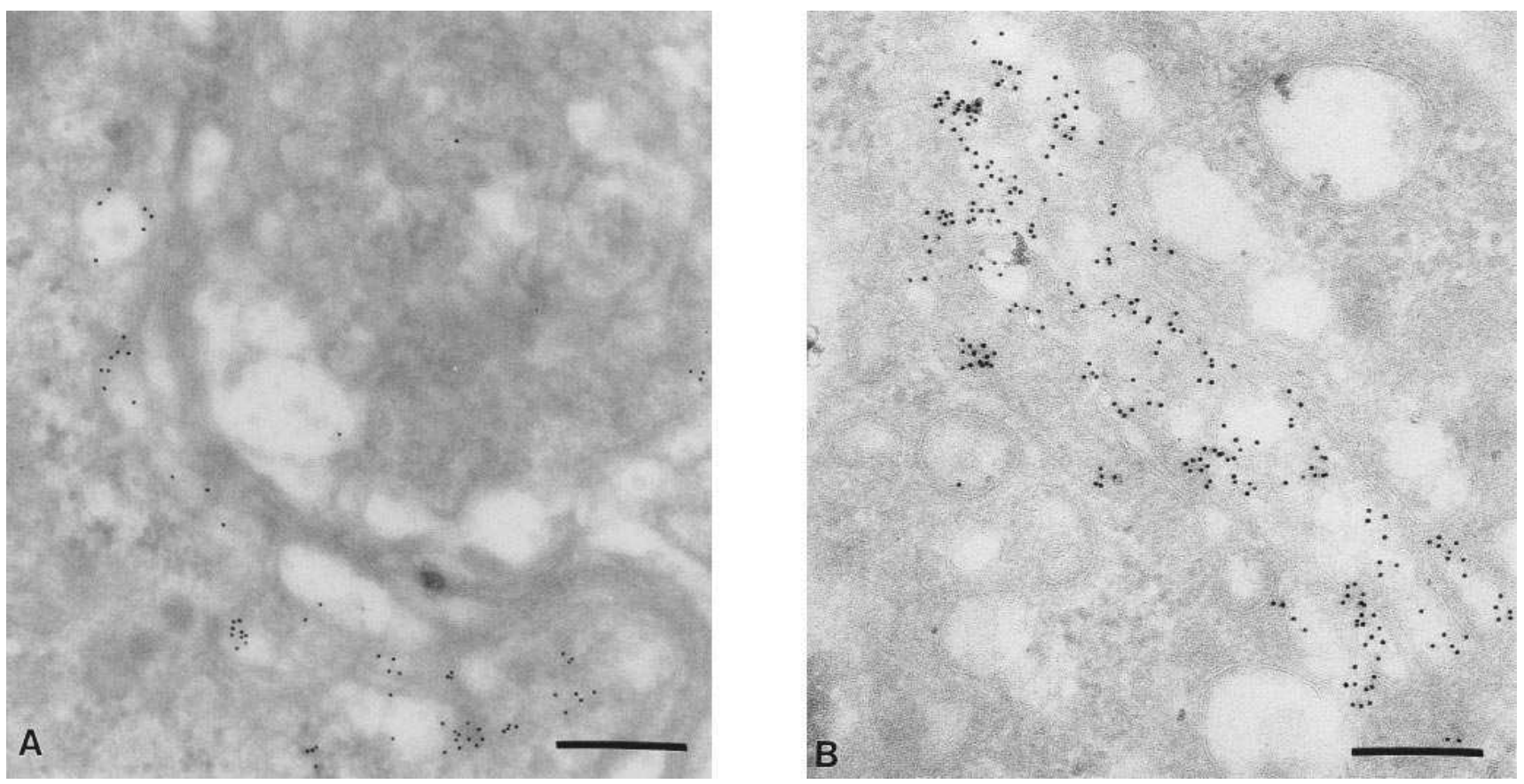

Figure 4. Immunocytochemical localization of ERGIC-53 in CSID and normal control. Localization of ERGIC-53 was performed on ultrathin cryosections from a control biopsy $(A)$ and from the patient's biopsy $(B)$ using antibody G1/93, followed by rabbit anti-mouse and protein A-10 nm gold staining. $(A)$ In the control biopsy vesicular structures on the cis-side of the Golgi apparatus are stained; $(B)$ in contrast, in the patient's biopsy the labeling is not only stronger, but also additional staining over cisternae on one side of the Golgi is observed. Morphologically the label coincides with that observed for SI (compare with Fig. $3 D$ ). Bar, $0.25 \mu \mathrm{m}$.

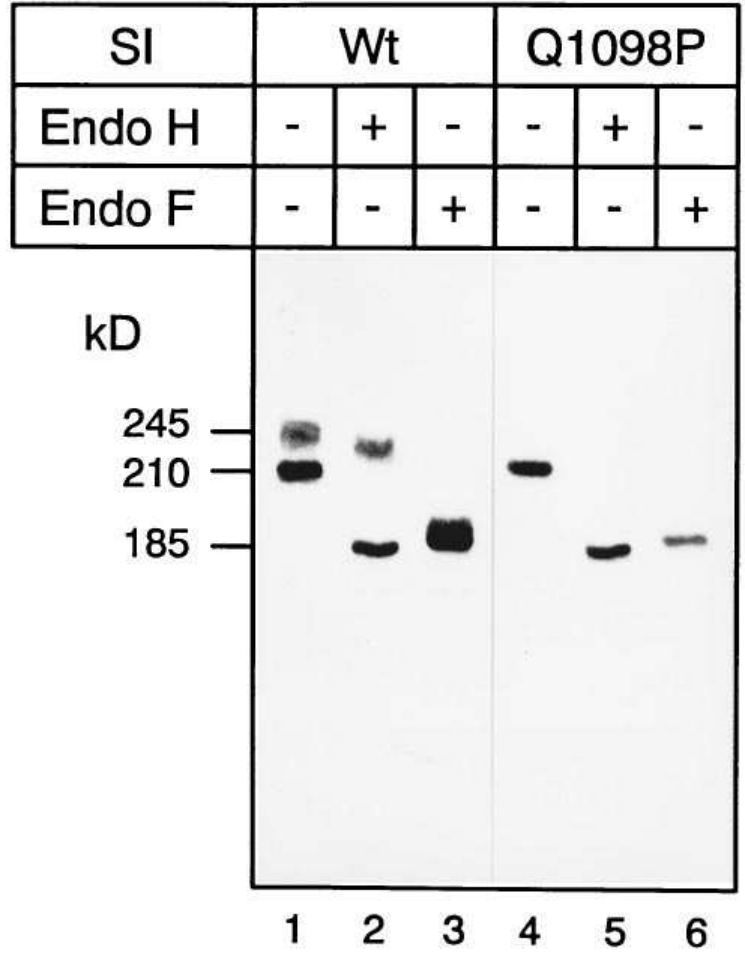

Figure 5. Expression of wild-type and mutant SI cDNA in COS-1 cells. COS-1 cells were transfected with phSI (lanes 1-3) or phSIa/c (lanes 4-6) plasmids and biosynthetically labeled with $\left[{ }^{35} \mathrm{~S}\right] \mathrm{methio-}$ nine for $6 \mathrm{~h}$. The cell extracts were immunoprecipitated with $\mathrm{mAb}$ anti-SI. The immunoprecipitates were analyzed by SDS-PAGE on $5 \%$ gels without treatment (lanes 1 and 4 ) or after Endo H (lanes 2 and 5) or Endo F treatment (lanes 3 and 6).
Upon comparison, lysosomal $\alpha$-glucosidase, Schwanniomyces occidentalis glucoamylase, sucrase, and isomaltase from various species share striking similarities in their amino acid sequences. This has led to the hypothesis that these molecules are derived from a common ancestral gene (39). Sequence comparison revealed that the mutation Q1098P in the S subunit is located in a stretch of 10 amino acids that is highly homologous among sucrase (amino acids 1093-1116), isomaltase (amino acids 219-243), lysosomal $\alpha$-glucosidase (amino acids 239-262) and Sch. occidentalis glucoamylase (amino acids 196220) (Fig. 7).

\section{Discussion}

CSID has been used to characterize various steps in the biosynthesis, transport, and sorting of SI as a model for cell surface membrane proteins. Several different phenotypes of CSID have been meanwhile described (14-17). In all of these CSID phenotypes, the transport incompetence, aberrant enzymatic function, or missorting to the basolateral membrane is exclusively restricted to the SI molecule, ruling out a possible general cellular defect.

While analyses of the current and previous phenotypes at the subcellular and protein levels lent strong support to the hypothesis that a point mutation in the cDNA of SI is responsible for the generation of CSID, the present data provide the first definite evidence that this is in fact the case. Here, we could characterize a point mutation in the region encoding the sucrase subunit of the SI complex which converts a glutamine to a proline (Q1098P).

Therefore, the CSID malabsorption is another example of a clinical disorder or disease that ensues by single amino acid 

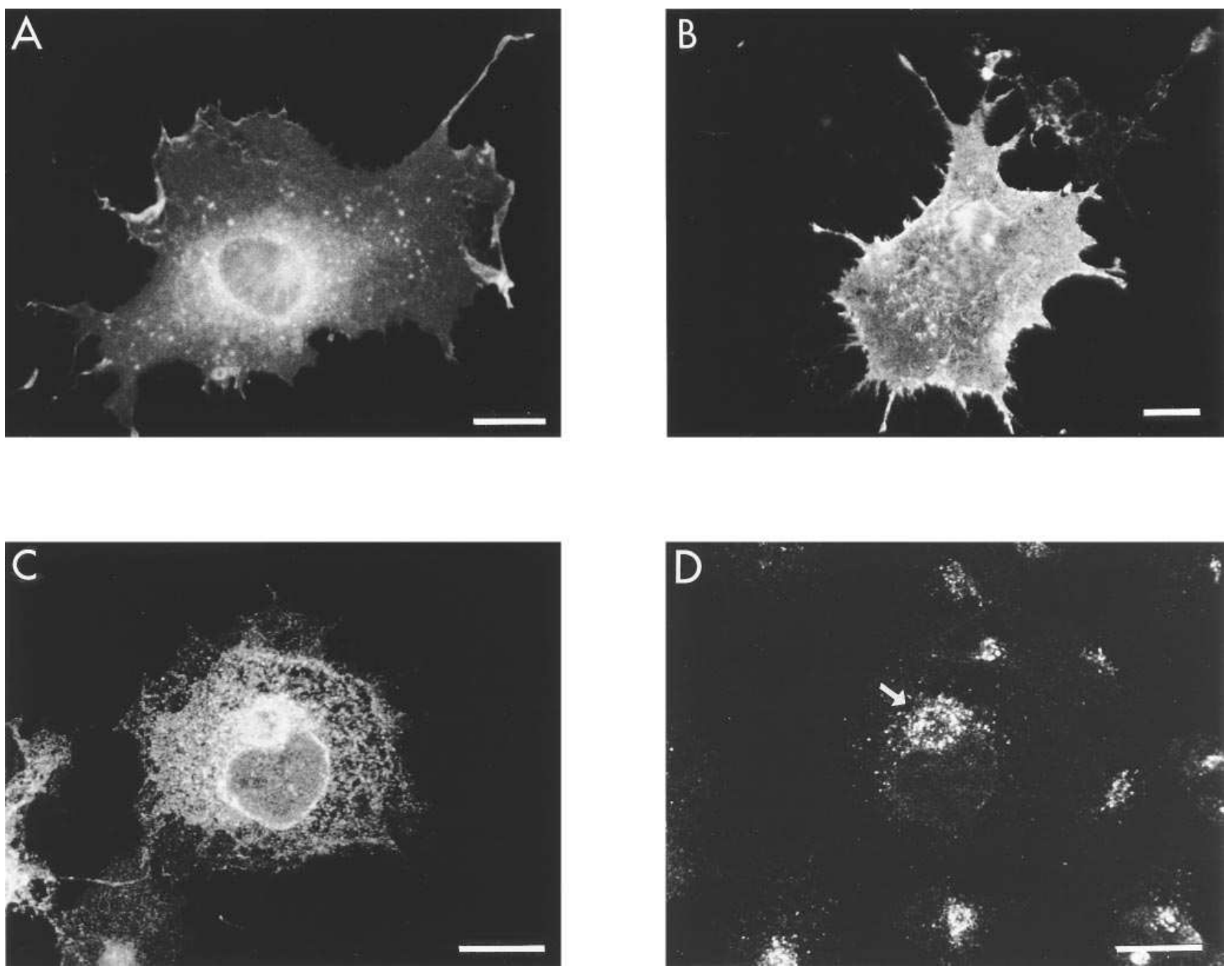

Figure 6. Immunofluorescence of wild-type and mutant SI cDNA in COS-1 cells. COS-1 cells were transfected with control SI cDNA $(A$ and $B)$ and Q1098P mutant SI cDNA $(C$ and $D)$. $(A)$ Control SI can be observed in the rough ER, Golgi, and cell surface of COS-cells; $(B)$ cell surface staining of control SI, see Methods for details of the procedure. ( $C$ and $D$ ) Immuno double-labeling of SI and ERGIC-53 in a COS cell transfected with mutant SI-cDNA and observed using a confocal scanning laser microscope equipped with a $\mathrm{Kr} / \mathrm{Ar}$ laser; $(C)$ immunostaining with HBB 2/614 anti-SI antibody in the ER and an ERGIC-53-positive compartment, note the absence of surface label (compare with $A$ ); $(D)$ immunostaining with G1/93 anti-ERGIC-53 antibody, note the structure (arrow) that is labeled both for SI $(C)$ and ERGIC-53 (D). Bar, $15 \mu \mathrm{m}$.

mutation in the polypeptide chain leading ultimately to dramatic alterations in the structural features, biosynthesis, posttranslational processing, transport, and function of cell surface and secretory proteins. While the CSID phenotype usually ends up in mild malabsorption of sugars and starch, the symptoms of which are readily identifiable, other disorders, such as cystic fibrosis (40), collagen-based diseases, and familial hypercholesterolemia (41), just to name a few, are more severe (for review see reference 13 ).

A rather unusual mutant form of SI is generated in CSID phenotype II. Here, SI exits the ER and is transported to the medial and trans-Golgi where it undergoes degradation (17). To our knowledge, no mammalian cell surface membrane glycoprotein has been so far identified that has efficiently egressed the ER and arrived in the Golgi cisternae where its transport is blocked. This strongly suggests that there are other criteria, in addition to the acquisition of correct folding and quaternary structure in the ER, that may modulate and control protein transport within the Golgi and to the cell surface.
The phenotype of SI described in this paper is very much similar to phenotype II (17). Analyses of the structural features of SI in this phenotype by epitope mapping and biosynthetic labeling reveal that incomplete initial folding of the SI precursor protein is responsible for the observed inefficient transport of the molecule along the secretory pathway. An effect of the oligomeric state of SI could be excluded since human SI does not dimerize and exits the ER efficiently as a monomeric molecule (8).

The most interesting aspect of phenotype II is the ability of SI to egress the ER to the Golgi, while still in an incompletely or partially folded state. The subsequent arrest and final degradation of SI in a cis-Golgi compartment or in the Golgi is unusual and, except for SI, has not been demonstrated for an endogenous protein destined for the cell surface. This is surprising since membrane and secretory proteins are believed to acquire transport competence in the ER and leave this organelle en route to their final destination.

It is generally accepted that a quality control mechanism 


\begin{tabular}{|rl|c|c|}
\hline & 1090 & 1100 & 110 \\
human sucrase & WDSWLPGFAFN & DQFIQISTRLPS & EY-IYGFGEVEH \\
rabbit sucrase & WDSCLPGFAFN & DQFIQISTRLPS & EY-IYGFGEAEH \\
rat sucrase & WDSSLPGFAFN & DQFIQISTRLPS & NY-LYGFGEVEH \\
human isomaltase & FDTSIGPLVYS & DQYLQISARLPS & DY-IYGIGEQVH \\
rabbit isomaltase & FDSSIGPLVYS & DQYLQISTRLPS & EY-MYGFGEHVH \\
human $\alpha$-glucosidase & LNTTVAPLFFA & DQFLQLSTSLPS & QY-ITGLAEHLS \\
SChw. 0. glucoamylase & FSTKGNPLVFS & NQFIQFNSSLPK & NHVITGLGESIH \\
& & & \\
& & &
\end{tabular}

Figure 7. Amino acid homology around the mutated region in the patient's SI. The amino acid sequences of normal human sucrase (32), rabbit sucrase (20), rat sucrase (45), human isomaltase (32), rabbit isomaltase (20), human lysosomal $\alpha$-glucosidase (43), and Sch. occidentalis glucoamylase (39) are aligned. The numbering and arrow indicate the position in this highly conserved region where in the patient's SI the Q1098P mutation is located.

exists in the ER that sorts correctly folded from malfolded proteins and retains the latter in the ER $(5-7,42)$. How could phenotype II of CSID be accommodated within these general views and concepts?

Human lysosomal $\alpha$-glucosidase (43) and the yeast $S c h . o c$ cidentalis glucoamylase (39) share striking homologies with human, rat, and rabbit $\mathrm{S}$ and I species and have been suggested to be evolved from a common ancestral gene (39). Of interest, the Q1098P mutation is located within a stretch of the S subunit that is homologous to lysosomal $\alpha$-glucosidase and Sch. occidentalis glucoamylase (Fig. 7). These proteins are all synthesized and translocated into the ER where they are processed to transport-competent forms and are then transported along the secretory pathway to their final destinations. While $\mathrm{SI}$ is sorted in the trans-Golgi network to the apical membrane, lysosomal $\alpha$-glucosidase is mainly transported to the lysosomes after phosphorylation in the cis-Golgi and maturation in the medial and trans-Golgi. Sch. occidentalis glucoamylase is transported to the periplasmic space and partially secreted into the exterior milieu in yeast. Obviously all three proteins share a common pathway from the ER to the Golgi and from there diverge to different destinations. Therefore, it is conceivable that homologies in the polypeptide sequences should be implicated in the biological function or transport mechanisms common to all of these proteins. Consistent with this is the observation that the regions containing the active catalytic centers of these proteins have almost identical amino acid sequences (34). If the mutation Q1098P does not initially induce gross conformational change in the $\mathrm{S}$ subunit, but rather alters a subdomain around the mutation that is critical for the intracellular transport of the SI protein or creates a retention signal, then a similar effect would be also expected if the mutation is introduced into the corresponding homologous regions of lysosomal $\alpha$-glucosidase or Sch. occidentalis glucoamylase.

It is possible that in the particular case of proteins with multidomain structure, such as SI, complete maturation of all protein domains is not absolutely required for egression from the ER, whereby the folding of some domains may be more essential or critical than others in the context of the overall conformation. SI is composed of two large homologous domains that may fold independently (Naim, H.Y., unpublished observations) and it is reasonable to assume that the presence of the mutation in the sucrase subunit leads to alterations in its structure while the entire isomaltase subunit remains unaffected. While these alterations could be tolerated by the quality con- trol mechanism in the ER, they could be crucial for the further secretory pathway of SI via the Golgi to the cell surface. Recent data with a temperature-sensitive mutant of vesicular stomatitis virus glycoprotein have proposed a quality control mechanism outside the ER that prevents immature vesicular stomatitis virus glycoprotein from traversing the Golgi (44). Mutant SI phenotype II may be subject to a similar mechanism that operates via a putative retention signal created by the Q1098P mutation.

We conclude that the simplest and most straight forward explanation for the phenotype described in this paper is that the mutation Q1098P has created a signal or conformational change in the sucrase subunit which retains the enzyme complex in a cis-Golgi compartment, where it is finally degraded by an unknown quality control mechanism operating at a level beyond the ER.

\section{Acknowledgments}

The first two authors on this paper have contributed equally to the work described.

We would like to thank Dr. J. Bartelsman (AMC, Amsterdam, The Netherlands) for providing us with the patient's biopsy material. We thank Dr. S.W. Lacey (Department of Internal Medicine, Division of Gastroenterology, University of Texas Southwestern Medical Center, Dallas, TX) for generously providing a partial cDNA clone of human SI (IM21.1).

Part of this work was supported by the Dutch Organization for Scientific Research (Medical Sciences, NWO-GBMW) and the Ministry for Research and Technology, BMFT (Bonn, Germany).

\section{References}

1. Griffiths, G., and K. Simons. 1986. The trans-Golgi network: sorting at the exit site of the Golgi complex. Science (Wash. DC). 234:438-443.

2. Hong, W., and B.L. Tang. 1993. Protein trafficking along the exocytic pathway. Bioessays. 15:231-238.

3. Louvard, D., M. Kedinger, and H.P. Hauri. 1992. The differentiating intestinal epithelial cell: establishment and maintenance of functions through interactions between cellular structures. Annu. Rev. Cell Biol. 8:157-195.

4. Rothman, J., and L. Orci. 1992. Molecular dissection of the secretory pathway. Nature (Lond.). 355:409-415.

5. Pelham, H.R.B. 1989. Control of protein exit from the endoplasmic reticulum. Annu. Rev. Cell Biol. 5:1-23.

6. Pfeffer, S.R., and J.E. Rothman. 1987. Biosynthetic protein transport and sorting by the endoplasmic reticulum and Golgi. Annu. Rev. Biochem. 56:829852.

7. Gething, M.J., K. McCammon, and J. Sambrook. 1989. Protein folding and intracellular transport: evaluation of conformational changes in nascent exocytotic proteins. Methods Cell Biol. 32:185-206.

8. Jascur, T., K. Matter, and H.P. Hauri. 1991. Oligomerization and intracellular protein transport: dimerization of intestinal dipeptidyl peptidase IV occurs in the Golgi apparatus. Biochemistry. 30:1908-1915.

9. Stieger, B., K. Matter, B. Baur, K. Bucher, M. Höchli, and H.P. Hauri. 1988. Dissection of the asynchronous transport of intestinal microvillar hydrolases to the cell surface. J. Cell Biol. 106:1853-1861.

10. Matter, K., M. Brauchbar, K. Bucher, and H.P. Hauri. 1990. Sorting of endogenous plasma membrane proteins occurs from two sites in cultured human intestinal epithelial cells (Caco-2). Cell. 60:429-437.

11. Matter, K., and H.P. Hauri. 1991. Intracellular transport and conformational maturation of intestinal brush border hydrolases. Biochemistry. 30:19161924.

12. Naim, H.Y. 1993. Human small intestinal angiotensin-converting enzyme - intracellular transport, secretion and glycosylation. Biochem. J. 296: 607-615.

13. Amara, J.F., S.H. Cheng, and A.E. Smith. 1992. Intracellular protein trafficking defects in human disease. Trends Cell Biol. 2:145-149.

14. Fransen, J.A.M., H.P. Hauri, L.A. Ginsel, and H.Y. Naim. 1991. Naturally occurring mutations in intestinal sucrase-isomaltase provide evidence for the existence of an intracellular sorting signal in the isomaltase subunit. J. Cell Biol. 115:45-57.

15. Hauri, H.P., J. Roth, E.E. Sterchi, and M.J. Lentze. 1985. Transport to 
cell surface of intestinal sucrase-isomaltase is blocked in the Golgi apparatus in a patient with congenital sucrase-isomaltase deficiency. Proc. Natl. Acad. Sci. USA. 82:4423-4427.

16. Lloyd, M.L., and W.A. Olsen. 1987. A study of the molecular pathology of sucrase-isomaltase deficiency. A defect in the intracellular processing of the enzyme. N. Engl. J. Med. 316:438-442.

17. Naim, H.Y., J. Roth, E.E. Sterchi, M. Lentze, P. Milla, J. Schmitz, and H.P. Hauri. 1988. Sucrase-isomaltase deficiency in humans. Different mutations disrupt transport, processing, and function of an intestinal brush border enzyme. J. Clin. Invest. 82:667-679.

18. Gorvel, J.P., A. Ferrero, L. Chambraud, A. Rigal, J. Bonicel, and S. Maroux. 1991. Expression of sucrase-isomaltase and dipeptidylpeptidase-IV in human small intestine and colon. Gastroenterology. 101:618-625.

19. Semenza, G. 1986. Anchoring and biosynthesis of stalked brush border membrane proteins: glycosidases and peptidases of enterocytes and renal tubuli. Annu. Rev. Cell Biol. 2:255-313.

20. Hunziker, W., M. Spiess, G. Semenza, and H. Lodish. 1986. The sucrase-isomaltase complex: primary structure membrane orientation, and evolution of a stalked, intrinsic brush border protein. Cell. 46:227-234.

21. Hauri, H.P. 1988. Biogenesis and intracellular transport of intestinal brush border membrane hydrolases. Subcell. Biochem. 12:155-219.

22. Naim, H.Y., E.E. Sterchi, and M.J. Lentze. 1988. Biosynthesis of the human sucrase-isomaltase complex. Differential $O$-glycosylation of the sucrase subunit correlates with its position within the enzyme complex. J. Biol. Chem. 263:7242-7253.

23. Hauri, H.P., A. Quaroni, and K.J. Isselbacher. 1979. Biogenesis of intestinal plasma membrane:posttranslational route and cleavage of sucraseisomaltase. Proc. Natl. Acad. Sci. USA. 76:5183-5186.

24. Pollak, M.R., Y.H.W. Chou, J.J. Cerda, B. Steinman, B.N. La Du, J.G. Seidman, and C.E. Seidman. 1993. Homozygosity mapping of the gene for alkaptonuria to chromosome 3q2. Nat. Genet. 5:201-204.

25. Hauri, H.P., E.E. Sterchi, D. Bienz, J.A.M. Fransen, and A. Marxer. 1985. Expression and intracellular transport of microvillus membrane hydrolases in human intestinal epithelial cells. J. Cell Biol. 101:838-851.

26. Schweizer, A., J.A.M. Fransen, T. Baechi, L. Ginsel, and H.P. Hauri. 1988. Identification, by a monoclonal antibody, of a 53-kD protein associated with a tubulo-vesicular compartment at the cis-side of the Golgi apparatus. $J$. Cell Biol. 107:1643-1653.

27. Dahlqvist, A. 1968. Assay of intestinal disaccharidases. Anal. Biochem. 22:99-107.

28. Naim, H.Y., E.E. Sterchi, and M.J.Lentze. 1987. Biosynthesis and maturation of lactase-phlorizin hydrolase in the human small intestinal epithelial cells. Biochem. J. 241:427-434.

29. Naim, H.Y., S.W. Lacey, J.F. Sambrook, and M.J.H. Gething. 1991. Expression of a full-length cDNA coding for human intestinal lactase-phlorizin hydrolase reveals an uncleaved, enzymatically active, and transport-competent protein. J. Biol. Chem. 266:12313-12320.

30. Sambrook, J., E.F. Fritsch, and T. Maniatis. 1989. Molecular Cloning: A Laboratory Manual. 2nd ed. Cold Spring Harbor Laboratory, Cold Spring Harbor, NY.
31. Moolenaar, C.E.C., C. Pieneman, F.S. Walsh, W.J. Mooi, and R.J.A.M. Michalides. 1992. Alternative splicing of neural-cell-adhesion molecule mRNA in human small-cell lung-cancer cell line H69. Int. J. Cancer. 51:238-243.

32. Davis, L.G., M.D. Dibner, and J.F. Battey. 1986. Basic Methods in Molecular Cloning. Elsevier, New York. 732 pp.

33. Innis, M.A., D.H. Gelfand, J.J. Sninsky, and T.J. White. 1990. PCR Protocols. A Guide to Methods and Applications. Academic Press, San Diego, CA.

34. Chantret, I., M. Lacasa, G. Chevalier, J. Ruf, I. Islam, N. Mantei, Y. Edwards, D. Swallow, and M. Rousset. 1992. Sequence of the complete cDNA and the $5^{\prime}$ structure of the human sucrase-isomaltase gene - possible homology with a yeast glucoamylase. Biochem. J. 285:915-923.

35. Green, F., Y. Edwards, H.P. Hauri, S. Povey, M.W. Ho, M. Pinto, and D. Swallow. 1987. Isolation of a cDNA probe for a human jejunal brush-border hydrolase, sucrase-isomaltase, and assignment of the gene locus to chromosome 3. Gene (Amst.). 57:101-110.

36. Brewer, C., and M. Roth. 1991. A single amino acid change in the cytoplasmic domain alters the polarized delivery of influenza virus hemagglutinin. $J$. Cell Biol. 114:413-421.

37. Fransen, J.A.M., L.A. Ginsel, H.P. Hauri, E. Sterchi, and J. Blok. 1985. Immuno-electronmicroscopical localization of a microvillus membrane disaccharidase in the human small-intestinal epithelium with monoclonal antibodies. Eur. J. Cell Biol. 38:6-15.

38. Laemmli, U.K. 1970. Cleavage of structural proteins during assembly of the head of bacteriophage $\mathrm{T}_{4}$. Nature (Lond.). 227:680-685.

39. Naim, H.Y., T. Niermann, U. Kleinhans, C.P. Hollenberg, and A.W.M. Strasser. 1991. Striking structural and functional similarities suggest that intestinal S-I, human lysosomal $\alpha$-glucosidase and Schwanniomyces occidentalis glucoamylase are derived from a common ancestral gene. FEBS Lett. 294:109-112.

40. Thomas, P.J., and P.L. Pedersen. 1993. Effects of the delta F508 mutation on the structure, function and folding of the first nucleotide-binding domain of CFTR. J. Bioenerg. Biomembr. 25:11-19.

41. Hobbs, H.H., M.S. Brown, and J.L. Goldstein. 1992. Molecular genetics of the LDL receptor gene in familial hypercholesterolemia. Hum. Mutat. 1:445466.

42. Balch, W.E., J.M. McCaffery, H. Plutner, and M.G. Farquhar. 1994. Ve sicular stomatitis virus glycoprotein is sorted and concentrated during export from the endoplasmic reticulum. Cell. 76:841-852.

43. Hoefsloot, L.H., M. Hoogeveen-Westerveld, M.A. Kroos, J. van Beumen, A. J.J. Reuser, and B. Oostra. 1988. Primary structure and processing of lysosomal alpha-glucosidase; homology with the intestinal sucrase-isomaltase complex. EMBO (Eur. Mol. Biol. Organ.) J. 7:1697-1704.

44. Hammond, C., and A. Helenius. 1994. Quality control in the secretory pathway: retention of a misfolded viral membrane glycoprotein involves cycling between the ER, intermediate compartment, and Golgi apparatus. J. Cell Biol. 126:41-52.

45. Broyart, J.P., J.P. Hugot, C. Perret, and A. Porteu. 1990. Molecular cloning and characterization of a rat intestinal sucrase-isomaltase cDNA. Regulation of sucrase-isomaltase gene expression by sucrose feeding. Biochim. Biophys. Acta. 1087:61-67. 